\title{
Degradação in vitro da fibra em detergente neutro de forragem tropical de baixa qualidade em função de suplementação com proteína e/ou carboidratos
}

\section{Viviane Aparecida Carli Costa ${ }^{1}$, Edenio Detmann², Sebastião de Campos Valadares Filho², Mário Fonseca Paulino ${ }^{2}$, Lara Toledo Henriques ${ }^{3}$, Hilário Cuquetto Mantovani ${ }^{4}$}

\author{
1 Programa de Pós-graduação em Zootecnia, Universidade Federal de Viçosa, Viçosa-MG, CEP: 36571-000. Bolsista do CNPq. \\ 2 DZO-UFV, Viçosa-MG. Pesquisador do CNPq. \\ ${ }^{3}$ Bolsista PRODOC-CAPES, DZO-UFV, Viçosa-MG \\ ${ }^{4}$ Departamento de Microbiologia, UFV, Viçosa-MG. Pesquisador do CNPq.
}

RESUMO - Objetivou-se avaliar o efeito da suplementação protéica e/ou com carboidratos sobre a degradação ruminal da fibra em detergente neutro (FDN) de forragem de baixa qualidade. Simulou-se a suplementação de bovinos em terminação, sob pastejo em Brachiaria decumbens de baixa qualidade, durante o período seco ( $70 \%$ de forragem e $30 \%$ de concentrado, com base na matéria seca). O concentrado referente ao tratamento base foi formulado de forma a apresentar $30 \%$ de proteína bruta, utilizando-se amido, como componente energético, e caseína, como componente protéico. Os tratamentos foram construídos a partir da omissão do fornecimento das fontes protéica e/ou energética do suplemento, associando-se, ainda, a substituição total do amido por pectina. Desta forma, seis foram os tratamentos avaliados: 1. forragem; 2 . forragem + amido; 3. forragem + pectina; 4. forragem + caseína; 5 . forragem + caseína + amido; e 6 . forragem + caseína + pectina. Os tratamentos foram avaliados em ambiente ruminal simulado por incubação in vitro e submetidos a diferentes tempos de incubação: 0,3 , $6,9,12,24,36,48,72$ e 96 horas. O procedimento de incubação foi repetido quatro vezes, perfazendo-se o total de quatro avaliações por tempo de incubação para cada tratamento. Os resíduos de incubação foram avaliados quanto ao teor de FDN e interpretados por intermédio de modelo não-linear logístico. Observou-se que a taxa de degradação da FDN potencialmente degradável (FDNpd) foi ampliada em cerca de 46\% com a suplementação com caseína, resultando em incrementos de 14,6\% sobre a fração efetivamente degradada. Observou-se efeito de menor amplitude com a inclusão ou alteração da fonte de carboidrato suplementar. A suplementação com amido causou redução na taxa de degradação da FDNpd, ao passo que a suplementação com pectina não afetou este parâmetro em comparação à ausência de carboidratos. Na presença de caseína, a suplementação com amido elevou o tempo de latência discreta para a degradação da FDN.

Palavras-chave: capim-braquiária, degradação ruminal, modelos matemáticos, suplementos

\section{In vitro degradation of low-quality tropical forage neutral detergent fiber according to protein and (or) carbohydrates supplementation}

\footnotetext{
ABSTRACT - The effect of the protein and (or) carbohydrates supplementation on the rumen degradation of neutral detergent fiber (NDF) from low quality forage was evaluated. The experiment simulated the supplementation of finishing cattle grazing low quality Brachiaria decumbens pasture during dry season (70:30 forage to concentrate ration, \%DM). The concentrate referring to the basal treatment was formulated to contain $30 \% \mathrm{CP}$, using starch as the energetic source and casein as the protein source. The treatments were established by omission of protein and (or) carbohydrates sources, associated with substitution of starch by pectin. In that way, six treatments were evaluated: 1. Forage, 2. Forage plus Starch, 3. Forage plus Pectin, 4.Forage plus Casein, 5. Forage plus casein plus starch and 6. Forage plus casein plus pectin. The treatments were evaluated under rumen environment, simulated by in vitro incubation, where the experimental diets were submitted to differen incubation periods: $0,3,6,9,12,24,36,48,72$, and 96 hours. The incubation procedure was repeated four times in a way that four evaluations within each incubation time were done for each treatment. The incubation residues were evaluated according to its contents of NDF and interpreted using a non-linear logistic model. It was observed that the degradation rate of potentially degradable NDF (pdNDF) was increased almost $46 \%$ with casein supplementation, resulting in an increment of $14.6 \%$ on the effective degraded fraction. A minor effect was observed with the inclusion or substitution of the supplemental carbohydrate source. The starch supplementation resulted in reduction on pdNDF degradation rate, whereas the supplementation with pectin did not affected this parameter, when compared to no carbohydrate supplementation. In the presence of casein, the starch supplementation raised the discrete lag time for NDF degradation.
}

Key Words: mathematical models, rumen degradation, signal grass, supplements 


\section{Introdução}

A forragem disponível em pastagens tropicais durante o período da seca apresenta apresenta elevado conteúdo de fibra e teores de proteína bruta (PB) geralmente inferiores a 7\%, valor considerado limitante para a adequada atividade dos microrganismos do rúmen (Minson, 1990), acarretando baixa digestibilidade da forragem, com o não-aproveitamento de energia potencialmente extraível dos carboidratos fibrosos da parede celular vegetal (Sampaio, 2007), e reduções no consumo voluntário e desempenho animal (Sniffen et al., 1993).

Esse quadro assume papel preponderante nos trópicos, pois, entre os diferentes componentes dos alimentos, a fração fibrosa apresenta importância fundamental em sistemas de produção, pois fornece quantidade significativa de energia a baixo custo. Dessa forma, baixa eficiência de aproveitamento da energia oriunda da fibra pode incorrer em redução nas eficiências produtiva e econômica dos sistemas de produção.

O fornecimento adicional de compostos nitrogenados para animais consumindo forragens de baixa qualidade pode, por sua vez, permitir incremento no consumo voluntário da forragem e melhorar o balanço energético a partir dos carboidratos fibrosos da forragem, uma vez que estes favorecem o crescimento das bactérias fibrolíticas (Russell et al., 1992), ampliando a taxa de degradação ruminal e a síntese de proteína microbiana, resultando em maior aporte de nutrientes para o intestino e ácidos graxos voláteis para o metabolismo energético (Detmann et al., 2004).

Nesse contexto, o aumento do consumo voluntário poderá resultar da ampliação na velocidade de degradação dos carboidratos fibrosos potencialmente degradáveis (Waldo et al., 1972; Sampaio, 2007), ampliando-se o turnover ruminal, tendo como conseqüência direta o aumento no consumo e degradação da FDN oriunda do pasto, fonte energética de maior viabilidade econômica.

Contudo, constitui desafio a predição da eficiência deste impacto sobre o desempenho animal, uma vez que, a despeito do embasamento teórico acima descrito, poucas informações estão disponíveis na literatura nacional acerca da influência real da suplementação com compostos nitrogenados sobre a dinâmica ruminal dos componentes fibrosos de forragens tropicais de baixa qualidade.

Por outro lado, depressões no consumo de forragem podem ocorrer sob baixas relações volumoso:concentrado da dieta (Minson, 1990), as quais podem ser facilmente verificadas em animais em terminação mantidos em pastagem quando o consumo de suplementos mantém-se em patamares próximos a 0,8-1,0\% do peso vivo (Paulino, 1999). Nestas circunstâncias, a redução no consumo de forragem pode ter conseqüência imediata sobre o rendimento produtivo do sistema, uma vez que se compromete a utilização dos componentes fibrosos da forragem como precursores para a síntese de produto animal.

Reduções no consumo de forragem podem ocorrer quando são fornecidos elevados níveis de carboidratos não-fibrosos (CNF) na dieta via suplementos, pois estes podem comprometer a utilização da fibra pelos microrganismos ruminais (Mould et al., 1983), o que prejudica o turnover das partículas presentes no rúmen (Souza, 2007).

No entanto, recentemente, tem-se estabelecido que os efeitos dos CNF podem se manifestar de forma diferenciada, em função da origem química dos carboidratos presentes nos suplementos (Arroquy et al., 2005). Dessa forma, faz-se necessária a investigação dos efeitos de CNF suplementares de diferentes origens químicas sobre a dinâmica ruminal dos carboidratos fibrosos da forragem, o que permitiria delinear com maior exatidão estratégias de suplementação para otimização do uso dos substratos energéticos basais de menor custo.

Assim, objetivou-se avaliar a dinâmica de degradação in vitro da FDN de forragem tropical de baixa qualidade, em função de suplementação com proteína e/ou diferentes fontes de carboidratos.

\section{Material e Métodos}

O experimento foi conduzido nas dependências do Laboratório de Nutrição Animal do Departamento de Zootecnia da Universidade Federal de Viçosa, Viçosa-MG.

A forragem avaliada foi proveniente de amostras de Brachiaria decumbens Stapf., colhidas por intermédio de cortes rente ao solo em piquetes sob pastejo contínuo, em Viçosa-MG, entre os meses de julho e agosto de 2003 (período seco).

A forragem, após secagem sob ventilação forçada $\left(60^{\circ} \mathrm{C} / 72 \mathrm{~h}\right)$, foi processada em moinho de facas com peneira de porosidade $1 \mathrm{~mm}$ e, posteriormente, analisada quanto aos teores de matéria seca (MS), matéria orgânica (MO), PB, extrato etéreo (EE), fibra em detergente ácido (FDA) e lignina por solubilização da celulose por ácido sulfúrico (72\% p/p), segundo métodos descritos em Silva \& Queiroz (2002). As avaliações dos teores FDN foram conduzidas segundo recomendações de Mertens (2002), empregando-se $\alpha$-amilase termoestável (Termamyl $120 \mathrm{~L}$ ), sem a utilização de sulfito de sódio. Os teores de FDN e FDA foram também expressos nas formas corrigidas para cinzas e compostos 
nitrogenados, sendo os procedimentos de correção conduzidos segundo métodos descritos por Mertens (2002) e Licitra et al. (1996), respectivamente.

O tratamento considerado como referência à implementação dos demais foi construído de forma a simular situação de suplementação para bovinos em terminação sob pastejo durante o período seco (70\% de forragem e $30 \%$ de concentrado, com base na MS), em aproximação a valores observados em experimentos similares in vivo (Kabeya et al., 2002; Detmann et al., 2004).

$\mathrm{O}$ concentrado referente ao tratamento referência foi formulado de forma a apresentar $30 \%$ de PB, utilizando-se amido, como componente energético, e caseína, como componente protéico. Todos os componentes utilizados nos procedimentos de incubação foram avaliados de forma similar aos métodos utilizados para as amostras de forragem (Tabela 1).

Os demais tratamentos foram construídos a partir da omissão do fornecimento da fonte protéica e/ou energética do suplemento, associando-se, ainda, a substituição total do amido por pectina. Dessa forma, seis foram os tratamentos avaliados: 1 . forragem; 2 forragem + amido; 3 forragem + pectina; 4. forragem + caseína; 5 . forragem + caseína + amido (tratamento referência); e 6. forragem + caseína + pectina.

A escolha dos componentes utilizados na constituição dos suplementos baseou-se na ausência de FDN, o que permitiu avaliar de forma exclusiva a degradação da fração fibrosa insolúvel da forragem. As seguintes fontes foram utilizadas: caseína oriunda do leite bovino (pó purificado;

Tabela 1 - Composição química da forragem e dos componentes dos suplementos

\begin{tabular}{|c|c|c|c|c|}
\hline \multirow[b]{2}{*}{ Item } & \multicolumn{4}{|c|}{ Componente } \\
\hline & Forragem & Amido & Pectina & Caseína \\
\hline $\mathrm{MS}^{1}$ & 749,2 & 880,5 & 854,4 & 901,3 \\
\hline $\mathrm{MO}^{2}$ & 931,4 & 989,1 & 967,4 & 978,7 \\
\hline $\mathrm{PB}^{2}$ & 38,3 & 0,0 & 36,8 & 878,9 \\
\hline $\mathrm{EE}^{2}$ & 6,4 & 1,2 & 3,7 & 5,6 \\
\hline $\mathrm{CT}^{2}$ & 886,7 & 987,9 & 926,9 & 94,2 \\
\hline $\mathrm{FDN}^{2}$ & 845,2 & - & - & - \\
\hline FDNcp ${ }^{2}$ & 781,0 & - & - & - \\
\hline PIDN $^{3}$ & 476,7 & - & - & - \\
\hline $\mathrm{CNF}^{2}$ & 105,7 & 987,9 & 926,9 & 94,2 \\
\hline FDA $^{2}$ & 476,0 & - & - & - \\
\hline FDAcp ${ }^{2}$ & 421,2 & - & - & - \\
\hline PIDA $^{3}$ & 326,9 & - & - & - \\
\hline Lignina $^{2}$ & 61,0 & - & - & - \\
\hline
\end{tabular}

$\mathrm{CT}=$ carboidratos totais $; \mathrm{PIDN}=$ proteína insolúvel em detergente neutro $\mathrm{CNF}=$ carboidratos não-fibrosos; FDAcp = fibra em detergente ácido corrigida para cinzas e proteína; PIDA = proteína insolúvel em detergente neutro.

$1 \mathrm{~g} / \mathrm{kg}$ de matéria natural.

$2 \mathrm{~g} / \mathrm{kg}$ de MS.

$3 \mathrm{~g} / \mathrm{kg}$ de PB.
Sigma C-5890); pectina cítrica (Sigma P-9135); e amido solúvel (PA, ACS, F. Maia S/A).

Alíquotas de forragem (245 mg de MS) foram acondicionadas em frascos de vidro tipo "penicilina" com $50 \mathrm{~mL}$ de volume total. Em seguida, adicionou-se a fonte protéica e/ou energética segundo a estrutura dos tratamentos anteriormente descritos, perfazendo o total de $350 \mathrm{mg}$ de MS por frasco para os tratamentos que envolveram, simultaneamente, as suplementações protéica e energética (Tabela 2). Posteriormente, foram adicionados $28 \mathrm{~mL}$ de solução tampão (McDougall, 1949), com $\mathrm{pH}$ previamente ajustado para 6,8 por intermédio de aspersão com $\mathrm{CO}_{2}$. Os frascos foram mantidos em sala climatizada $\left(39^{\circ} \mathrm{C}\right)$ para prévia hidratação das amostras.

Durante o processo de hidratação, foi coletado líquido ruminal proveniente de um bovino doador, fistulado no rúmen, mantido nas proximidades da sala de incubação. $\mathrm{O}$ animal doador foi alimentado exclusivamente com cana-deaçúcar, sem correção com uréia, sendo submetido a jejum de alimentos por 12 horas anteriormente à coleta. A alimentação base do animal doador, em conjunto com o período de jejum, visou à obtenção de inóculo ruminal com baixo teor de nitrogênio amoniacal, buscando-se simular as condições ruminais de animais mantidos em pastos tropicais durante o período seco, sem suplementação. $\mathrm{O}$ animal teve disponibilidade irrestrita no tocante à água e mistura mineral completa ( $6 \%$ de fósforo).

Olíquido foi coletado na região de interface líquido: sólido do ambiente ruminal, filtrado por uma camada tripla de gaze, acondicionado em recipiente térmico e imediatamente transportado à sala de incubação.

Foram adicionados $7 \mathrm{~mL}$ de inóculo ruminal por frasco, procedendo-se imediatamente à saturação do ambiente de incubação com $\mathrm{CO}_{2}$ e à vedação dos frascos. A relação final para os tratamentos com a adição de suplementos protéico e energético foi de $100 \mathrm{mg}$ de $\mathrm{MS} / 10 \mathrm{~mL}$ de solução final e $1 \mathrm{~mL}$ de inóculo ruminal/4 $\mathrm{mL}$ de solução tampão (Tilley \& Terry, 1963). Os frascos foram mantidos a $39^{\circ} \mathrm{C}$, sob agitação orbital $(40 \mathrm{rpm})$. Procedeu-se à retirada dos gases oriundos da fermentação a cada três horas com o auxílio de agulhas.

Foram avaliados os tempos de $0,3,6,9,12,24,36$, 48, 72 e 96 horas de incubação. O procedimento de incubação foi repetido quatro vezes, perfazendo-se o total de quatro avaliações por tempo de incubação para cada tratamento.

Ao final de cada tempo de incubação, os frascos foram retirados da sala climatizada e submetidos à mensuração do pH com potenciômetro digital, sendo o conteúdo filtrado a vácuo em cadinhos filtrantes (porosidade grossa). Os cadinhos foram então acondicionados em frascos de 
Tabela 2 - Descrição dos componentes adicionados ao sistema in vitro de acordo com os diferentes tratamentos

\begin{tabular}{|c|c|c|c|c|c|c|}
\hline \multirow[b]{2}{*}{ Componente } & \multicolumn{6}{|c|}{ Tratamento ${ }^{1}$} \\
\hline & $\mathrm{F}$ & FA & $\mathrm{FP}$ & $\mathrm{FC}$ & FCA & $\mathrm{FCP}$ \\
\hline Forragem $(\mathrm{mg})^{2}$ & 245 & 245 & 245 & 245 & 245 & 245 \\
\hline Amido $(\mathrm{mg})^{2}$ & - & 65 & - & - & 65 & - \\
\hline Pectina $(\mathrm{mg})^{2}$ & - & - & 65 & - & - & 65 \\
\hline Caseína $(\mathrm{mg})^{2}$ & - & - & - & 40 & 40 & 40 \\
\hline Inóculo ruminal $(\mathrm{mL})^{3}$ & 7 & 7 & 7 & 7 & 7 & 7 \\
\hline Tampão de McDougall (mL) & 28 & 28 & 28 & 28 & 28 & 28 \\
\hline
\end{tabular}

${ }^{1} \mathrm{~F}=$ forragem; $\mathrm{FA}=$ forragem mais amido; $\mathrm{FP}=$ forragem mais pectina; FC = forragem mais caseína; FCA = forragem mais caseína e amido; e FCP = forragem mais caseína e pectina.

2 Com base na matéria seca.

${ }^{3} \mathrm{O}$ inóculo ruminal apresentou teor médio de $6,17 \mathrm{mg}$ de nitrogênio amoniacal/dL.

polietileno $(120 \mathrm{~mL})$, aos quais se adicionaram $50 \mathrm{~mL}$ de detergente neutro (Mertens, 2002). Após serem vedados, os frascos foram autoclavados $\left(105^{\circ} \mathrm{C} / 1\right.$ hora $)$, de forma a extraírem-se todos os componentes solúveis em detergente neutro (técnica de micro-extração; Pell \& Schofield, 1993). Após este tratamento, procedeu-se novamente à filtração sob vácuo e lavagem seqüencial do resíduo com água quente e acetona. A FDN residual foi obtida após secagem do material em estufa não-ventilada $\left(105^{\circ} \mathrm{C} / 16\right.$ horas $)$.

Os resíduos de FDN nos diferentes tempos, para cada tratamento, foram submetidos, por intermédio do algoritmo de Gauss-Newton, ao ajustamento do modelo logístico nãolinear descrito por Van Milgen et al. (1991):

$$
R t=U \times \frac{[c \times \exp (-p \times t)-p \times \exp (-c \times t)]}{(c-p)}+I
$$

em que: $\mathrm{Rt}$ = resíduo não-degradado de FDN no tempo " $\mathrm{t}$ " (\%); U = fração potencialmente degradável da FDN (\%); I = fração indegradável da FDN (\%); c = taxa fracional de degradação da fração potencialmente degradável da FDN $\left(\mathrm{h}^{-1}\right) ; \mathrm{p}=$ taxa fracional de latência $\left(\mathrm{h}^{-1}\right) ; \mathrm{e} \mathrm{t}=$ tempo $(\mathrm{h})$.

A função descrita em (1) é simétrica em relação às taxas fracionais c e p, sendo comumente assumido que os menores valores estão associados ao parâmetro c (Van Milgen et al., 1991). Contudo, para os casos em que c e p tendem à mesma estimativa, indeterminação matemática será observada. Assim, para os casos em que isto foi observado, o modelo foi re-parametrizado, segundo a regra de L'Hôspital (Van Milgen et al., 1991):

$R t=U \times(1+\lambda \times t) \times \exp (-\lambda \times t)+I$

em que: 1 = taxa fracional conjunta de latência e degradação $\left(\mathrm{h}^{-1}\right)$, sendo os demais termos definidos anteriormente.

Em virtude de o parâmetro $\lambda$ representar conjuntamente as taxas de latência e degradação, impossibilita-se a comparação biológica direta com o parâmetro c (Equação 1).
Desta forma, estimou-se a taxa fracional de degradação a partir de $\lambda$, utilizando-se as propriedades da distribuição gama-2 (Ellis et al., 1994):

$c^{\prime}=0,59635 \lambda$

em que: c' = taxa fracional de degradação da FDN potencialmente degradável $\left(\mathrm{h}^{-1}\right)$ para os casos em que o modelo re-parametrizado for utilizado (Equação 2).

As estimativas de latência discreta foram obtidas segundo derivações de Vieira et al. (1997):

$L=\frac{R(0)-R\left(t_{i}\right)}{\mu}+t_{i}$

em que: $\mathrm{L}=$ latência discreta $(\mathrm{h}) ; \mathrm{R}(0)=$ resíduo de FDN nãodegradado em $\mathrm{t}=0(\%) ; \mathrm{R}\left(\mathrm{t}_{\mathrm{j}}\right)$ = resíduo não-degradado de FDN obtido no ponto de inflexão da curva de degradação (\%); $\mu$ = derivada da curva ajustada de degradação para o ponto de inflexão (máxima taxa de degradação do substrato) $\left(\mathrm{h}^{-1}\right) ; \mathrm{t}_{\mathrm{i}}=$ tempo equivalente ao ponto de inflexão da curva de degradação (h).

Os valores de $t_{i}$ foram obtidos segundo as descrições de Van Milgen et al. (1991) e Vieira et al. (1997), segundo as equações abaixo, aplicadas, respectivamente, aos modelos descritos em (1) e (2):

$t_{i}=\frac{\ln (c)-\ln (p)}{(c-p)}$

$t_{i}=\frac{1}{\lambda}$

As frações efetivamente degradadas da FDN foram obtidas em adaptação às sugestões de Ørskov \& McDonald (1979), segundo a equação:

$F E D=\lim _{t \rightarrow \infty} \int_{0}^{t}\left[f(t) \times\left(-\frac{d R t}{d t}\right)\right] d t$

em que: $\mathrm{FED}=$ fração efetivamente degradada da $\operatorname{FDN}(\%)$; 
$f(\mathrm{t})$ = função relativa ao deslocamento de sólidos no ambiente ruminal.

Para definição da função descrita em (7), assumiu-se deslocamento ruminal de sólidos de ordem gama-1 (Ellis et al., 1994), segundo a equação:

$$
f(t)=\exp (-k \times t)
$$

em que: $\mathrm{k}=$ taxa fracional de deslocamento de sólidos no ambiente ruminal $\left(\mathrm{h}^{-1}\right)$, à qual se designaram, hipoteticamente, os valores $0,020,0,035$ e 0,050 .

Desta forma, estimou-se FED, no contexto das equações (1) e (2), respectivamente, por:

$$
\begin{aligned}
& F E D=U \times \frac{c \times p}{(c+k) \times(p+k)} \\
& F E D=U \times \frac{\lambda^{2}}{(\lambda+k)^{2}}
\end{aligned}
$$

O efeito de repleção ruminal da fração potencialmente degradável da FDN (FDNpd) foi obtido em adaptação às proposições de Waldo et al. (1972), respectivamente, para o uso das equações (1) e (2):

$R R=\lim _{t \rightarrow \infty} \int_{0}^{t}\left\{U p \times \frac{[c \times \exp (-p \times t)-p \times \exp (-c \times t)]}{(c-p)} \times f(t)\right\} d t=U p \times \frac{c+p+k}{(c+k) \times(p+k)}$ (11);

$R R=\lim _{t \rightarrow \infty} \int_{0}^{t}\{U p \times(1+\lambda \times t) \times \exp (-\lambda \times t) \times f(t)\} d t=U p \times \frac{2 \lambda+k}{(\lambda+k)^{2}}$

$(12)$;

em que: $\mathrm{RR}=$ efeito de repleção ruminal da FDNpd (h); e $\mathrm{Up}=$ fração potencialmente degradável da FDN padronizada, sendo $U p=U /(U+I)$.

A taxa específica de crescimento microbiano sobre a FDNpd foi estimada segundo proposições de Beuvink \& Kogut (1993), segundo a equação:

$S g r=\frac{\mu}{U}$

em que: $\mathrm{Sgr}=$ taxa específica de crescimento microbiano $\left(\mathrm{h}^{-1}\right)$.

A partir das estimativas de Sgr, obtiveram-se as eficiências de crescimento microbiano, segundo proposições de Pirt (1965):

$\frac{1}{Y}=\frac{m}{S g r}+\frac{1}{Y m}$

em que: $\mathrm{Y}=$ eficiência microbiana $\left(\mathrm{g}\right.$ células $\times \mathrm{g}^{-1}$ carboidrato degradado); $\mathrm{m}=$ exigência de mantença das bactérias $\left(\mathrm{g}\right.$ carboidrato $\times \mathrm{g}^{-1}$ célula $\left.\times \mathrm{h}^{-1}\right)$; e Ym = eficiência teórica máxima dos microrganismos sobre o substrato ( $\mathrm{g}$ células $\times \mathrm{g}^{-1}$ carboidratos).
Adotou-se como referência ao parâmetro Ym o valor de 0,4 g célula $\times \mathrm{g}^{-1}$ carboidrato degradado e para $\mathrm{m}$ o valor de $0,05 \mathrm{~g}$ de carboidratos $\times \mathrm{g}^{-1}$ célula $\times \mathrm{h}^{-1}$, conforme especificações de Russell et al. (1992).

Os modelos ajustados para os perfis de degradação em função dos diferentes tratamentos foram comparados de forma descritiva. Por sua vez, os valores de $\mathrm{pH}$ obtidos para os diferentes tempos de incubação foram avaliados segundo delineamento em blocos completos casualizados, considerando-se cada partida de incubação como bloco, em esquema fatorial $2 \times 3 \times 10$ (ausência ou presença de suplementação com compostos nitrogenados; três fontes de carboidratos; e dez tempos de incubação). Todos os procedimentos estatísticos, tanto lineares como não-lineares, foram conduzidos por intermédio do programa Statistical Analysis System (SAS, 1989), adotando-se 0,05 como nível crítico de probabilidade para o erro tipo I.

\section{Resultados e Discussão}

Verificou-se diferença sobre a conformação dos perfis de degradação com ou sem a adição de caseína (Figura 1; Tabela 3). Na ausência de caseína, verificou-se perfeita discriminação entre os parâmetros c e p (Equação 1). Por outro lado, na presença de caseína, verificou-se tendência de similaridade entre estes, demandando a re-parametrização do modelo (Van Milgen et al., 1991) com a adoção de taxa conjunta de latência e degradação ( $\lambda$; Equação 2$)$.

Embora comparações biológicas não possam ser aplicadas diretamente entre os parâmetros c e $\lambda$; este, ao ser convertido à forma c' (Equação 2), permitiu evidenciar incremento, em média da ordem de $46,0 \%$ sobre a taxa de

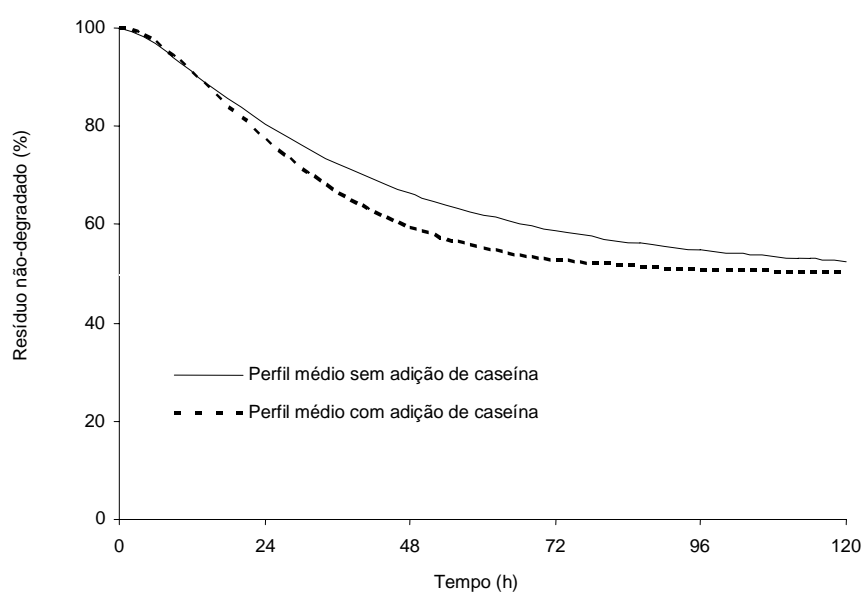

Figura 1 - Estimativa média do perfil de degradação da FDN em função da suplementação com caseína. 
Tabela 3 - Estimativas da taxa fracional de degradação da FDNpd $\left(c-\mathrm{h}^{-1}\right)$, taxa fracional de latência $\left(\mathrm{p}-\mathrm{h}^{-1}\right)$, taxa fracional comum para latência e degradação $\left(\lambda-\mathrm{h}^{-1}\right)$, taxa fracional de degradação da FDNpd obtida a partir da conversão do parâmetro I $\left(c^{\prime}-h^{-1}\right)$ e latência discreta $(L-h)$, desvios-padrão assintóticos (DPA) e número de observações (n) para os perfis de degradação ajustados para os diferentes tratamentos

\begin{tabular}{|c|c|c|c|c|c|c|}
\hline \multirow[b]{2}{*}{ Parâmetro } & \multicolumn{6}{|c|}{ Tratamento 1} \\
\hline & $\mathrm{F}$ & FA & $\mathrm{FP}$ & $\mathrm{FC}$ & $\mathrm{FCA}$ & $\mathrm{FCP}$ \\
\hline $\mathrm{c}$ & $0,0279 \pm 0,014$ & $0,0215 \pm 0,006$ & $0,0288 \pm 0,009$ & - & - & - \\
\hline $\mathrm{p}$ & $0,1578 \pm 0,175$ & $0,1736 \pm 0,101$ & $0,2923 \pm 0,329$ & - & - & - \\
\hline$\lambda$ & - & - & - & $0,0682 \pm 0,006$ & $0,0554 \pm 0,003$ & $0,0679 \pm 0,052$ \\
\hline$c^{\prime}$ & - & - & - & 0,0407 & 0,0330 & 0,0405 \\
\hline $\mathrm{L}$ & 3,52 & 3,51 & 2,21 & 4,13 & 5,09 & 4,15 \\
\hline DPA & 5,44 & 2,67 & 4,88 & 4,17 & 2,90 & 4,18 \\
\hline $\mathrm{n}^{2}$ & 39 & 33 & 38 & 39 & 40 & 39 \\
\hline
\end{tabular}

degradação ruminal da FDNpd com a suplementação com compostos nitrogenados (Tabela 3).

O incremento obtido sobre a taxa de degradação da FDNpd com a introdução de compostos nitrogenados suplementares pode ser melhor visualizado por intermédio da Figura 1. Ressalta-se que as estimativas demonstradas no gráfico, bem como o processo de estimação das demais variáveis apresentadas nesta pesquisa, foram baseadas nos valores médios gerais das frações U $(49,8 \pm 2,1 \%)$ e I $(50,1 \pm 1,9 \%)$, sob o pressuposto de estas serem características únicas e exclusivas do substrato (forragem) (Ørskov, 2000).

Ao contrário do impacto direto verificado com a adição de compostos nitrogenados, a suplementação com carboidratos produziu efeitos de menor magnitude sobre a taxa de degradação da FDNpd (Tabela 3).

A pectina conferiu taxas de degradação análogas à ausência de carboidratos, tanto na ausência, como na presença de caseína (Tabela 3). Efeitos deste composto foram, contudo, verificados sobre a latência discreta, resultando, na ausência de caseína, em redução de $37,2 \%$ e, na presença de caseína, em valores similares aos observados sem a presença de carboidratos, respectivamente (Tabela 3 ).

Por outro lado, a influência do amido mostrou-se negativa sobre a degradação da FDNpd tanto na ausência, como na presença de caseína (Tabela 3). Na ausência de caseína, a suplementação com amido reduziu em $22,9 \%$ a taxa de degradação da FDNpd, embora nenhum impacto tenha sido verificado sobre a latência. De outra forma, na presença de caseína, o amido reduziu em $18,9 \%$ a taxa de degradação da FDNpd e, concomitantemente, elevou em 23,0\% a latência.

O modelo adotado para descrição do perfil de degradação da FDN (Equação 1) pressupõe que o processo de degradação ruminal seja composto por dois sub-compartimentos: o primeiro, onde ocorreriam os eventos preparató- rios à degradação (hidratação, fixação microbiana, etc) (Van Soest, 1994), que alimentaria dinamicamente, à taxa $p$, o sub-compartimento no qual ocorreria efetivamente a degradação, segundo a taxa c (Van Milgen et al., 1991).

A similaridade entre as estimativas dos parâmetros c e $\mathrm{p}$ verificadas para os casos em que se procedeu à suplementação com compostos nitrogenados constitui indicativo indireto de maior velocidade de ação microbiana sobre o substrato, uma vez que os eventos preparatórios tendem a ocorrer de forma quase simultânea à degradação, tornando os sub-compartimentos menos distinguíveis, sendo sua dinâmica expressa por uma taxa conjunta $(\lambda)$ (Equação 2).

De fato, a inclusão de compostos nitrogenados incrementou, em média, em 22,4 e $10,5 \%$ a taxa de crescimento específica e a eficiência de crescimento dos microrganismos sobre a FDNpd (Tabela 4).

$\mathrm{O}$ incremento na taxa de degradação da FDNpd por intermédio da adição de compostos nitrogenados, em contraste às variações de menor magnitude observadas com a adição ou alteração da fonte de carboidrato, indica a natureza prioritária da proteína na suplementação de animais mantidos em pastagens durante a estação seca, situação na qual a extração de energia a partir dos carboidratos fibrosos torna-se limitada por deficiência de compostos nitrogenados para a síntese dos sistemas enzimáticos dos microrganismos ruminais (Satter \& Slyter, 1974; Leng, 1990; Paulino et al., 2006; Sampaio, 2007).

Segundo Satter \& Slyter (1974), a produção de proteína microbiana e o rendimento microbiano sobre o substrato energético são linearmente incrementados com a elevação dos níveis de PB da dieta até limites em torno de 130 a $140 \mathrm{~g} / \mathrm{kg}$. A produção de proteína microbiana está diretamente relacionada à velocidade de utilização dos substratos energéticos, que está intimamente associada à taxa de 
Tabela 4 - Máxima taxa de degradação $\left(\mu-\mathrm{h}^{-1}\right)$, taxa específica de crescimento de microrganismos $\left(S g r-h^{-1}\right)$ e eficiência de crescimento microbiano sobre a FDNpd (EFM - g MS microbiana/kg de carboidrato degradado no rúmen), em função dos diferentes tratamentos

\begin{tabular}{lccc}
\hline Tratamento $^{1}$ & $\mu$ & Sgr & EFM \\
\hline F & 0,9578 & 0,0192 & 195,9 \\
FA & 0,7971 & 0,0160 & 177,8 \\
FP & 1,1135 & 0,0224 & 211,3 \\
\hline Média s/ caseína & 0,9561 & 0,0192 & 195,0 \\
\hline FC & 1,2497 & 0,0250 & 222,2 \\
FCA & 1,0151 & 0,0204 & 202,0 \\
FCP & 1,2442 & 0,0250 & 222,2 \\
\hline Média c/ caseína & 1,1697 & 0,0235 & 215,5 \\
\hline Incremento médio c/ caseína $(\%)$ & 22,3 & 22,4 & 10,5 \\
\hline
\end{tabular}

$1 \mathrm{~F}=$ forragem; $\mathrm{FA}=$ forragem mais amido; $\mathrm{FP}=$ forragem mais pectina; $F C=$ forragem mais caseína; $F C A$ = forragem mais caseína e amido; e $\mathrm{FCP}=$ forragem mais caseína e pectina.

degradação da FDNpd em dietas baseadas em forragem de baixa qualidade (Sampaio, 2007), relação que suporta o incremento nas estimativas deste último parâmetro com a suplementação com compostos nitrogenados.

As exigências de compostos nitrogenados dos microrganismos ruminais deixam de ser atendidas em níveis dietéticos basais de PB inferiores a $70 \mathrm{~g} / \mathrm{kg}$, comprometendo a utilização dos substratos energéticos potencialmente disponíveis (Van Soest, 1994; Sampaio, 2007). Níveis protéicos inferiores a este foram observados na forragem basal utilizada neste estudo (Tabela 1) e são comumente verificados na forragem disponível ao pastejo em condições tropicais durante o período da seca (Paulino et al., 2002).

Por outro lado, Paulino et al. (2006) descreveram que limitações severas no tocante à disponibilidade de compostos nitrogenados podem comprometer não somente a velocidade de utilização, mas impor limitações de acessibilidade (ou extensão de degradação) à FDNpd.

Por se tratar de parâmetro diretamente derivado da taxa de degradação da FDNpd, o comportamento verificado mostrou-se similar aos desta variável, com incrementos, considerando-se taxa de passagem de $0,035 \mathrm{~h}^{-1}$, de $17,1 \%$ sobre a fração efetivamente degradada da FDNpd, em função da introdução de compostos nitrogenados suplementares, indicando acréscimo na acessibilidade dos substratos energéticos da forragem basal.

Segundo Sampaio (2007), o nível mínimo de 70 g/kg de PB na dieta basal é demandado para que os microrganismos tenham condições de utilização dos substratos energéticos fibrosos potencialmente degradáveis em forragens tropicais de baixa qualidade. Essa afirmativa suporta o incremento na fração de FDNpd efetivamente degradada obtida neste
Tabela 5 - Estimativas da fração efetivamente degradada da fibra em detergente neutro potencialmente degradável (\% da FDNpd) em função dos diferentes tratamentos

\begin{tabular}{|c|c|c|c|}
\hline \multirow[b]{2}{*}{ Tratamento ${ }^{1}$} & \multicolumn{3}{|c|}{$\begin{array}{l}\text { Taxa de passagem ruminal } \\
\qquad\left(\mathrm{h}^{-1}\right)^{2}\end{array}$} \\
\hline & 0,020 & 0,035 & 0,050 \\
\hline $\mathrm{F}$ & 51,70 & 36,30 & 27,20 \\
\hline FA & 46,46 & 31,66 & 23,35 \\
\hline FP & 55,23 & 40,31 & 31,22 \\
\hline Média s/ caseína & 51,13 & 36,09 & 27,26 \\
\hline $\mathrm{FC}$ & 59,79 & 43,67 & 33,29 \\
\hline FCA & 53,99 & 37,56 & 27,62 \\
\hline $\mathrm{FCP}$ & 59,67 & 43,55 & 33,17 \\
\hline Média c/ caseína & 57,81 & 41,59 & 31,36 \\
\hline Incremento médio c/ caseína $(\%)$ & 14,3 & 17,1 & 17,8 \\
\hline \multicolumn{4}{|c|}{$\begin{array}{l}{ }^{1} \mathrm{~F}=\text { forragem; } F A=\text { forragem mais amido; } F P=\text { forragem mais pectina; } \\
F C=\text { forragem mais caseína; } F C A=\text { forragem mais caseína e amido; } \\
\text { e FCP = forragem mais caseína e pectina. } \\
2 \text { Assumindo-se cinética de deslocamento ruminal de sólidos com ordem } \\
\text { gama-1. }\end{array}$} \\
\hline
\end{tabular}

trabalho, uma vez que o mínimo de compostos nitrogenados não foi suprido pela forragem basal (Tabela 1).

Ressalta-se que incrementos na fração efetivamente degradada da FDNpd evidenciam aumentos na fração energética total da dieta oriunda dos carboidratos fibrosos da forragem, podendo implicar diretamente em redução dos custos de produção animal.

Verificou-se decréscimo médio de 9,8\% sobre as estimativas do efeito de repleção ruminal da FDNpd com a introdução de compostos nitrogenados suplementares (Tabela 6).

O efeito de repleção ruminal representa de forma integrada a dinâmica do desaparecimento da FDN no ambiente ruminal, estando inversamente relacionado à capacidade de consumo de fibra (Waldo et al., 1972; Paulino et al., 2006). Desta forma, os benefícios obtidos com a suplementação com compostos nitrogenados integrar-se-iam sobre a FDNpd, implicando tanto em ampliação de sua degradação pelos microrganismos ruminais (Tabela 5), como em incremento na capacidade animal em ingeri-la (Tabela 6) (Paulino et al., 2006).

Esse comportamento mostrou-se similar ao obtido por Sampaio (2007), que verificou relação linear positiva entre a suplementação com compostos nitrogenados e o consumo de FDN efetivamente digerida em bovinos alimentados com forragem tropical de baixa qualidade. Estímulos sobre o consumo de forragem frente à suplementação protéica foram também relatados por Hannah et al. (1991), Köster et al. (1996) e Mathis et al. (2001). 
Tabela 6 - Efeito de repleção ruminal da ruminal (h) da FDNpd em função dos diferentes tratamentos

\begin{tabular}{lccc}
\hline & \multicolumn{3}{c}{ Taxa de passagem ruminal } \\
$\left(\mathrm{h}^{-1}\right)^{2}$ \\
\cline { 2 - 4 } Tratamento $^{1}$ & 0,020 & 0,035 & 0,050 \\
\hline F & 12,0 & 9,1 & 7,3 \\
FA & 13,3 & 9,7 & 7,6 \\
FP & 11,2 & 8,5 & 6,9 \\
\hline Média s/ caseína & 12,2 & 9,1 & 7,3 \\
\hline FC & 10,0 & 8,0 & 6,7 \\
FCA & 11,5 & 8,9 & 7,2 \\
FCP & 10,1 & 8,0 & 6,7 \\
\hline Média c/ caseína & 10,5 & 8,3 & 6,8 \\
\hline Decréscimo médio c/ caseína $(\%)$ & 13,9 & 9,8 & 6,8 \\
\hline
\end{tabular}

${ }^{1} \mathrm{~F}=$ forragem; $\mathrm{FA}$ = forragem mais amido; $\mathrm{FP}$ = forragem mais pectina; $F C=$ forragem mais caseína; $F C A$ = forragem mais caseína e amido; e $\mathrm{FCP}=$ forragem mais caseína e pectina.

${ }^{2}$ Assumindo-se cinética de deslocamento ruminal de sólidos com ordem gama-1.

A probabilidade de retirada de uma partícula fibrosa do ambiente ruminal se eleva à medida que a FDNpd é degradada, permitindo ampliar a concentração dos componentes de maior densidade, representados pela porção indegradável da FDN (FDNi) (Allen, 1996). Desta forma, incrementos sobre a taxa de degradação da FDNpd implicam em reduções na repleção ruminal (Equações 11 e 12). Contudo, os processos de trânsito e degradação mostram-se interligados, sendo que incrementos na taxa de degradação, além de reduzirem diretamente o efeito de repleção ruminal da FDNpd, propiciam incrementos sobre a taxa de passagem ruminal (Paulino et al., 2006). Isto indica que os efeitos sobre a repleção ruminal seriam muito mais proeminentes in vivo do que aqueles observados in vitro (Tabela 6), uma vez que não se considera o trânsito ruminal.

Em função de seu efeito secundário sobre o processo de degradação ruminal da fibra, em relação aos efeitos propiciados pelos compostos nitrogenados (Tabela 3), os carboidratos devem ser avaliados de forma secundária, visando-se identificar relações sinérgicas ou antagônicas.

Como verificado neste experimento, a suplementação com carboidratos não introduziu benefícios sobre a utilização dos recursos basais, acarretando, em alguns casos, efeitos deletérios sobre a utilização da FDNpd (Tabelas 3, 5 e 6).

A queda na degradação ruminal da fibra frente à suplementação com carboidratos não-fibrosos (CNF) pode ser atribuída a dois efeitos distintos, denominados efeito pH e efeito concentrado ou efeito carboidrato (Mould et al., 1983; Arroquy et al., 2005). No primeiro caso, reduções significativas no $\mathrm{pH}$ ruminal são responsáveis pela inibi- ção parcial da degradação fibrosa, por comprometerem a condição ideal de meio para o crescimento dos microrganismos fibrolíticos (Mould et al., 1983; Hoover, 1986; Van Soest, 1994).

A investigação do $\mathrm{pH}$ do meio de incubação não permitiu evidenciar efeitos significativos da suplementação com compostos nitrogenados $(\mathrm{P}>0,05)$ ou efeitos de interação de qualquer natureza $(\mathrm{P}>0,05)$. Por outro lado, verificaram-se efeitos significativos sobre esta variável no tocante à suplementação com carboidratos e ao tempo de incubação $(\mathrm{P}<0,05)$ (Figura 2).

Verificou-se efeito quadrático $(\mathrm{P}<0,05)$ em função do tempo de incubação, com ponto crítico localizado em 45,3 horas (Figura 2). Ressalta-se que as fontes de carboidratos não diferiram entre si quanto ao $\mathrm{pH}$ ruminal $(\mathrm{P}>0,05)$, propiciando, no entanto, valores inferiores aos observados na ausência de carboidratos $(\mathrm{P}<0,05)$. Contudo, a suplementação com carboidratos não propiciou valores de $\mathrm{pH}$ considerados danosos à atividade microbiana sobre os carboidratos fibrosos da forragem (Mould et al., 1983; Hoover, 1986), indicando, com grande possibilidade, ausência de influência do efeito $\mathrm{pH}$ sobre a degradação da FDNpd na presença de carboidratos suplementares. Desta forma, o efeito carboidrato parece ter predominado sobre o comportamento observado neste estudo.

De forma geral, como discutido anteriormente, efeitos deletérios sobre a utilização da FDNpd foram observados com a suplementação com amido (Tabela 3), comportamento que concorda com relatos de outros autores (ElShazly et al., 1961; Mertens \& Loften, 1980; Piwonka \& Firkins, 1993; Haddad \& Grant, 2000; Arroquy et al., 2005).

$\mathrm{O}$ efeito carboidrato verificado com a adição de amido parece envolver a competição por nutrientes essenciais entre grupos microbianos, resultando em maior proliferação dos microrganismos que degradam amido (El-Shazly et al., 1961; Coelho da Silva \& Leão, 1979; Mould et al., 1983). Esta competição conduziria à preferência inicial pela utilização do amido como substrato energético no ambiente ruminal (El-Shazly et al., 1961), com a transformação gradativa da fibra em substrato energético predominante, à medida que se reduz a disponibilidade de amido (El-Shazly et al., 1961; Mertens \& Loften, 1980; Arroquy et al., 2005), envolvendo, desta forma, mecanismos de regulação catabólica (Russell \& Baldwin, 1978).

Por outro lado, alguns autores têm reportado a inibição da atividade de enzimas fibrolíticas em função da presença de amido no meio (Hiltner \& Dehority, 1983, citados por Arroquy et al., 2005; Piwonka \& Firkins, 1993), fato que parece estar associado à liberação de compostos inibidores 


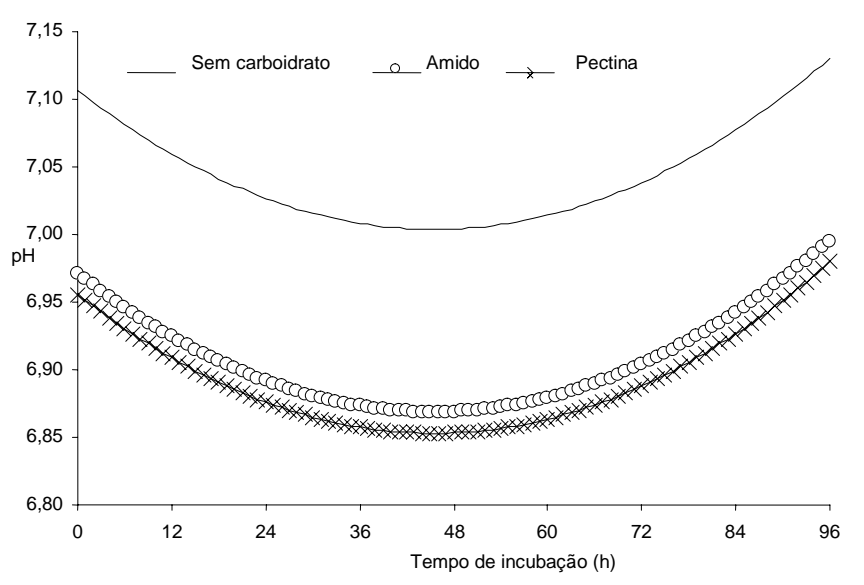

Figura 2 - Estimativas do pH do meio de incubação em função do tempo e das fontes de carboidratos no suplemento $\left(\hat{Y}=7,1066-0,1351 D_{1}-0,1507 D_{2}-0,00452 T+\right.$ $0,00004966 T^{2} ; R^{2}=0,6943$; em que: $D_{1}=1$, para amido, e $\mathrm{D}_{1}=0$, caso contrário; e $\mathrm{D}_{2}=1$, para pectina, e $D_{2}=0$, caso contrário)

pelos microrganismos que degradam o amido (El-Shazly et al., 1961), os quais parecem ser de natureza protéica (bacteriocinas) (Piwonka \& Firkins, 1993; Kalmokoff et al., 1996).

A união destes argumentos implica em retardo no processo de degradação da FDNpd, como verificado neste trabalho (Tabela 3).

Embora alguns autores pressuponham que outras formas de CNF ajam similarmente ao amido (Arroquy et al., 2005), os resultados obtidos nesta pesquisa indicam que a suplementação com pectina não incorre em efeitos deletérios à ação microbiana sobre a FDNpd (Tabela 3).

A pectina, embora sendo CNF, constitui polissacarídeo não-amiláceo (fibra solúvel), assumindo papel estrutural na célula vegetal. Desta forma, apresenta processo de fermentação microbiana predominantemente acético, similar à celulose e à hemicelulose (Van Soest, 1994), o que parece constituir a principal causa da ausência de efeitos deletérios sobre a utilização da FDNpd.

A redução na latência discreta verificada com a suplementação com pectina na ausência de caseína (Tabela 3 ) parece estar relacionada ao seu pequeno conteúdo em compostos nitrogenados (Tabela 1), não sendo, em essência, efeito direto de sua presença no meio.

\section{Conclusões}

A suplementação de forragem de baixa qualidade com compostos nitrogenados apresenta natureza prioritária, pois incrementa a utilização dos carboidratos fibrosos pelos microrganismos ruminais. A suplementação com carboidratos apresenta aspectos secundários sobre a utilização da fibra da forragem, sendo verificados efeitos inibitórios in vitro sobre a utilização da fibra basal, quando as fontes de carboidratos são baseadas em amido, ou efeitos pouco representativos, quando utilizada a pectina. 0

\section{Literatura Citada}

ALLEN, M.S. Physical constrains on voluntary intake of forages by ruminants. Journal of Animal Science, v.74, p.30633075, 1996.

ARROQUY, J.I.; COCHRAN, R.C.; NAGARAJA, T.G. et al. Effect of types of non-fiber carbohydrate on in vitro forage fiber digestion of low-quality grass hay. Animal Feed Science and Technology, v.120, p.93-106, 2005.

BEUVINK, J.M.W.; KOGUT, J. Modeling gas production kinetics of grass silages incubated in ruminal fluid. Journal of Animal Science, v.71, p.1041-1046, 1993.

COELHO DA SILVA, J.F.; LEÃO, M.I. Fundamentos de nutrição dos ruminantes. Piracicaba: Livroceres, 1979. 380p.

DETMANN, E.; PAULINO, M.F.; ZERVOUDAKIS, J.T. et al. Níveis de proteína bruta em suplementos múltiplos para terminação de novilhos mestiços em pastejo durante a época seca: desempenho produtivo e características de carcaça. Revista Brasileira de Zootecnia, v.33, p.169-180, 2004.

ELLIS, W.C.; MATIS, J.H.; HILL, T.M. et al. Methodology for estimating digestion and passage kinetics of forages. In: FAHEY JR., G.C. (Ed.) Forage quality, evaluation, and utilization. Madison: American Society of Agronomy, 1994. p.682-756.

EL-SHAZLY, K; DEHORITY, B.A.; JOHSON, R.R. Effect of starch on the digestion of cellulose in vitro and in vivo by rumen microorganisms. Journal of Animal Science, v.20, p.268273, 1961.

HADDAD, S.G.; GRANT, R.J. Influence of nonfiber carbohydrate concentration on forage fiber digestion in vitro. Animal Feed Science and Technology, v.86, p.107-115, 2000.

HANNAH, S.M.; COCHRAN, R.C.; VANZANT, E.S. et al. In Influence of protein supplementation on site and extent of digestion, forage intake, and nutrient flow characteristics in steers consuming dormant Bluestem-Range forage. Journal of Animal Science, v.69, p.2624-2633, 1991.

HOOVER, W.H. Chemical factors involved in ruminal fiber digestion. Journal of Animal Science, v.63, p.40-44, 1986.

KABEYA, K.S.; PAULINO, M.F.; DETMANN, E. et al. Suplementação de novilhos mestiços em pastejo na época de transição águas-seca: desempenho produtivo, características físicas de carcaça, consumo e parâmetros ruminais. Revista Brasileira de Zootecnia, v.31, p.213-222, 2002.

KALMOKOFF, M.L.; BARTLETT, F.; TEATHER, R.M. Are ruminal bacteria armed with bacteriocins? Journal of Animal Science, v.79, p.2297-2306, 1996.

KÖSTER, H.H.; COCHRAN, R.C.; TITGEMEYER, E.C. et al. Effect of increasing degradable intake protein on intake and digestion of low-quality tallgrass-prairie forage by beef cows. Journal of Animal Science, v.74, p.2473-2481, 1996.

LENG, R.A. Factors affecting the utilization of "poor-quality" forages by ruminants particularly under tropical conditions. Nutrition Research Review, v.3, p.277-303, 1990.

LICITRA, G.; HERNANDES, T.M.; van SOEST, P.J. Standardization of procedures for nitrogen fractionation of ruminant feeds. Animal Feed Science and Technology, v.57, p.347-358, 1996. 
MATHIS, C.P.; COCHRAN, R.C.; HELDT, J.S. et al. Effects of supplemental degradable intake protein on utilization of medium to low-quality forages. Journal of Animal Science, v.78, p.224-232, 2001

McDOUGALL, E. I. Studies on ruminal saliva. 1. The composition and output of sheep's saliva. Biochemistry Journal, v.43, p.99-109, 1949.

MERTENS, D.R. Gravimetric determination of amylase-treated neutral detergent fibre in feeds with refluxing beakers or crucibles: collaborative study. Journal of AOAC International, v.85, p.1217-1240, 2002.

MERTENS, D.R.; LOFTEN, J R. The effect of starch on forage fiber digestion kinetics in vitro. Journal of Dairy Science, v.63, p.1437-1446, 1980 .

MINSON, D.J. Forage in ruminant nutrition. San Diego: Academic Press, 1990. 483p.

MOULD, F.L.; ØRSKOV, E.R.; MANNS, O. Associative effects of mixed feeds. I. Effects of type and level of supplementation and the influence of the rumen $\mathrm{pH}$ on cellulolysis in vivo and dry matter digestion of various roughages. Animal Feed Science and Technology, v.10, p.15-30, 1983.

ØRSKOV, E.R. The in situ technique for the estimation of forage degradability in ruminants. In: GIVENS, D.I.; OWEN, E.; AXFORD, R.F.E. et al. (Eds.) Forage evaluation in ruminant nutrition. London: CAB International, 2000. p.175-188.

ØRSKOV, E.R.; McDONALD, I. The estimation of protein degradability in the rumen from incubation measurements of feed in weighted according to rate passage. Journal of Agricultural Science, v.92, p.499-503, 1979.

PAULINO, M.F. Estratégias de suplementação para bovinos em pastejo. In: SIMPÓSIO DE PRODUÇÃO DE GADO DE CORTE, 1., 1999, Viçosa, MG. Anais... Viçosa, MG: SIMCORTE, 1999. p.137-156.

PAULINO, M.F.; ZERVOUDAKIS, J.T.; MORAES, E.H.B.K. et al. Suplementação múltipla para bovinocultura de ciclo curto em pastagens. In: SIMPÓSIO DE PRODUÇÃO DE GADO DE CORTE, 3., 2002, Viçosa, MG. Anais... Viçosa, MG: SIMCORTE, 2002. p.199-242.

PAULINO, M.F.; DETMANN, E.; VALADARES FILHO, S.C. Suplementação animal em pasto: energética ou protéica? In: SIMPÓSIO SOBRE MANEJO ESTRATÉGICO DA PASTAGEM, 3., 2006, Viçosa, MG. Anais... Viçosa, MG: Universidade Federal de Viçosa, 2006. p.359-392.

PELL, A.N.; SCHOFILD, P. Computerized monitoring of gas production to measure forage digestion in vitro. Journal of Dairy Science, v.76, p.1063-1073, 1993.

PIRT, S.J. The maintenance energy of bacteria in growing cultures. Proceedings of Royal Society, Series B, v.163, p.224-231, 1965.
PIWONKA, E.J.; FIRKINS, J.L. Effect of glucose fermentation on fiber digestion by ruminal microorganisms in vitro. Journal of Dairy Science, v.79, p.2196-2206, 1993.

RUSSELL, J.B.; BALDWIN, R.L. Substrate preferences in rumen bacteria: evidence of catabolic regulatory mechanisms. Applied and Environmental Microbiology, v.36, p.319$329,1978$.

RUSSELL, J.B.; O'CONNOR, J.D.; FOX D.G. et al. A net carbohydrate and protein system for evaluating cattle diets: I. Ruminal fermentation. Journal of Animal Science, v.70, p.3551-3561, 1992.

SAMPAIO, C.B. Consumo, digestibilidade e dinâmica ruminal bovinos alimentados com forragem tropical de baixa qualidade suplementados com compostos nitrogenados. Viçosa, MG: Universidade Federal de Viçosa, 2007, 54p. Dissertação (Mestrado em Zootecnia) - Universidade Federal de Viçosa, 2007.

STATISTICAL ANALYSIS SYSTEM - SAS. SAS/STAT user's guide. 4.ed. Cary: SAS Institute, 1989. v.2., 846p.

SATTER, L.D.; SLYTER, L.L. Effect of ammonia concentration on rumen microbial protein production in vitro. British Jornal of Nutrition, v.32, p.199-208,1974.

SILVA, D.J.; QUEIROZ, A.C. Análise de alimentos: métodos químicos e biológicos. 3.ed. Viçosa, MG: Editora UFV, 2002. 235p.

SNIFFEN, C.J.; BEVERLY, R.W.; MOONEY, C.S. et al. Nutrient requirements versus supply in the dairy cow: strategies to account for variability. Journal of Dairy Science, v.76, p.3160-3178, 1993.

SOUZA, M.A. Consumo, digestibilidade e dinâmica ruminal em bovinos alimentados com forragem tropical de baixa qualidade e suplementados com compostos nitrogenados e/ou carboidratos. Viçosa, MG: Universidade Federal de Viçosa, 2007. 44p. Dissertação (Mestrado em Zootecnia) - Universidade Federal de Viçosa, 2007.

TILLEY, J.M.A.; TERRY, R.A. A two-stage technique for the in vitro digestion of forage crops. Journal of British Grassland Society, v.18, p.104-111, 1963.

Van MILGEN, J.; MURPHY, L.L.; BERGER, L.L. A compartmental model to analyze ruminal digestion. Journal of Dairy Science, v.74, p.2515-2529, 1991.

Van SOEST, P.J. Nutritional ecology of the ruminant. 2.ed. Ithaca: Cornell University Press, 1994. 476p.

VIEIRA, R.A.M.; PEREIRA, J.C.; MALAFAIA, P.A.M. et al. The influence of elephantgrass (Pennisetum purpurem Schum. Mineiro variety) growth on the nutrient kinetics in the rumem. Animal Feed Science and Technology, v.66, p.197-210, 1997.

WALDO, D.R.; SMITH, L.W.; COX, E.L. Model of cellulose disappearance from the rumen. Journal of Dairy Science, v.55, p.125-129, 1972 . 